\title{
UN EJEMPLO DE LA LABOR TRADICIONAL EN EL ROMANCERO VIEJO
}

El romance de La hija del rey de Francia y el caballero burlado, conocido desde el siglo $\mathrm{XV}$, vive todavía en la tradición oral (contaminado por lo general, y desde antiguo, con otros dos: La infantina encantada y Don Bueso). Su proceso de tradicionalización es no sólo de los más antiguos, sino también uno de los más palpables: sin detenernos a considerar el casi seguro origen francés de la historia que narra ${ }^{1}$, y dejando también a un lado, por el momento, sus vicisitudes en la tradición oral moderna, la comparación de las versiones antiguas de este romance permite advertir la activa labor de la tradición en el transcurso de unas pocas décadas.

El romance de La hija del rey de Francia es uno de los más antiguos entre aquellos cuyo texto puede fecharse con alguna seguridad. Figura en un cancionero manuscrito existente en el British Museum, y se atribuye en él, lo mismo que otras dos versiones de romances viejos (Rosaflorida y el Conde Arnaldos), a Juan Rodríguez del Padrón. Como éste murió hacia 1450, Morley, en su cronología de los más antiguos romances, coloca estos tres en el segundo lugar, hacia 1440, precedidos solamente por el Gentil dona que hacia 1421 copió Jaume de Olesa². "Confieso que la atribución a Juan Rodríguez me parece muy dudosa", dice Menéndez Pelayo (Antología de poetas líricos, $1^{\mathrm{a}}$ ed., vol. XI, pág. 10, nota 2). Morley transcribe esta opinión y agrega que BaIsT (en GRPh, II, $2^{\mathrm{a}}$ parte, pág. 433) no sólo aceptaba a Rodríguez del Padrón como autor de estas versiones, "sino que parecía pensar que compuso los tres poemas y que luego éstos fueron adoptados y transmitidos por el pueblo". Según María Rosa Lida de Malkiel (NRFH, VI, 1952, págs. 320-

\footnotetext{
${ }^{1}$ El origen francés de La hija del rey de Francia -y también el de La infantina encantada-, cuya indagación se sale de los límites de este estudio, ha sido aceptado por toda la crítica. "Amador de los Ríos -dice, sin embargo, Puy maigre - a aussi recueilli un chant analogue dans les Asturies (Hist. crit., VI, p. 442), mais voulant toujours réserver la priorité à sa patrie, et ne semblant pas connaître les similaires français, il le prétend original" (Romanceiro, Paris, 1881, págs. $221-222$ ).

"S: G. Morley, "Chronological list of early Spanish ballads", en HR, XIII, 1945, págs. 273-287.
} 
321 ), "no hay argumento irrefutable" para negar al poeta gallego la paternidad de los tres romances, y la atribución de Rosaflorida y de La hija del rey de Francia en especial "no suscita dificultad alguna". RENNERT, editor del cancionero manuscrito de Londres, opina que deberían atribuirse a Macías. Si no se acepta la atribución a Rodríguez del Padrón, queda en pie la fecha del manuscrito (Cancionero MS. Add. $1043^{1}$ del British Museum: es el ms. $N$ de Mussafia $^{3}$ ), que, según Rennert, es posterior a 1471 y anterior a 1500 .

Los tres romances atribuídos a Rodríguez del Padrón fueron publicados por Hugo RenNerT en $Z R P h$, XVII, 1893, págs. 544-558, y luego reproducidos por Menéndez Pelayo en su Antología, XII, págs. 541-542. El texto del que nos interesa es el siguiente, según la edición de Rennert (loc. cit., pág. 555):

Yo me iba para Francia do padre y madre tenía; errado abía el camino, errado abía la vía;

5 arryméme a un castillo por atender compañía. Por y viene un escudero, cabalgando a la su gisa. - ¿Qué fazes aý, donzella, 1o tan sola y sin conpanía? -Yo me iba para Francia do padre y madre tenía, errado abía el camino, errado abía la vía;

15 si te plaze, el escudero, llébesme en tu conpanía. -Plázeme, dijo, señora, sí faré por cortesía, y a las ancas de un caballo

20 él tomado la abía. Allá en los Montes Claros de amores la rrequería.

-Tate, tate, el escudero, no fagáys descortesia:

25 fija soy de un malato, lleno es de malatía, y si bos a mí llegades luego se vos pegaría. Andando jornadas çiertas

3o a Françia llegado abía. Allí fabló la doncella, bien oyrés lo que diría: -E[s] cobarde el escudero, bien lleno de cobardía,

35 tubo la niña en sus braços y no supo servilla.

Rennert corrige, en el verso 17 , dijo, donde el ms. trae dilo. Menéndez Pelayo moderniza las grafías como "guisa", etc. (dejando intactas, según corresponde, las formas de valor sonoro real: fija, faces, etc.), quita el inútil paréntesis del verso 25 , y varía el último: "pero no supo servilla".

Esta redacción muestra, evidentemente, un estado primitivo del romance: repetición innecesaria de una serie de cuatro versos; paso de una forma personal, egocéntrica, a la narrativa; inclusión de una

${ }^{3}$ La edición del ms. londinense la hizo Rennert en $R F, \mathrm{X}, 1899$, págs. 1-176. Para lo referente a los romances en él contenidos, véase Morley, art. cit.-Adolfo Mussaria, "Per la bibliografia dei Cancioneros spagnuoli", sep. de Denkschriften der Kaiserlichen Akademie der Wissenschaften in Wien, Philos.-hist. Klasse, Band XLVII, 2, 1900. 
precisión topográfica (los Montes Claros), que la tradición se encargará de hacer desaparecer.

El romance existe también en una versión ampliada (cincuenta y dos versos), que pasará del Cancionero de romances sin año (fols. $259 \mathrm{r}^{0}-260 \mathrm{r}^{\circ}$ al de $155^{\circ}$ y a la Silva del mismo año, y que reproducirán, con variantes más o menos leves, todos los editores modernos del romance: Grimm, Depping-Galiano, Durán, Wolf y Hofmann, Menéndez Pelayo ${ }^{4}$. He aquí el texto, tal como aparece en el Cancionero de romances sin año (ed. facsímil de Menéndez Pidal, Madrid, 1945), modernizadas sólo la puntuación, la acentuación y las mayúsculas:

De Francia partió la niña,

de Francia la bien guarnida;

ýuase para París,

do padre y madre tenía.

5 Errado lleua el camino, errada lleua la guía; arrimárase a vn roble por esperar compañía. Vió venir vn cauallero,

1o que a París lleua la guía. La niña desque lo vido desta suerte le dezía: -Si te plaze, cauallero, lléuesme en tu compañía.

15 -Plázeme, dixo, señora, plázeme, dixo, mi vida. Apeóse del cauallo por hazelle cortesia; puso la niña en las ancas

20 y él subiérase en la silla. En el medio del camino de amores la requeria. La niña desque lo oyera dixole con osadía:

25 - Tate, tate, cauallero, no hagáys tal villanía, hija soy de vn malato y de vna malatía, el hombre que a mí llegasse

30 malato se tornaría. El cauallero con temor palabra no respondía.

A la entrada de París la niña se sonrreýa.

$35-$ De qué vos reýs, señora, de qué vos reýs, mi vida? -Ríome del cauallero y de su gran couardía: tener la niña en el campo

40 y catarle cortesía. Cauallero con vergüença estas palabras dezía: -Buelta, buelta, mi señora, que vna cosa se me oluida.

45 La niña, como discreta, dixo: -Yo no boluería, ni persona, aunque boluiesse, en mi cuerpo tocaría. Hija soy del rey de Francia

$5^{\circ}$ y de la reyna Constantina; el hombre que mí llegasse mui caro le costaría.

4 Jacobo Grimm, Silva de romances viejos, págs. $25^{0-2} 5^{1}$ de las ediciones de 1815 y 1831 . Creo que ambas ediciones son en realidad una sola. He podido ver dos ejemplares de la segunda: uno que pertenecía a don Arturo Marasso, y el de la B.N.P. Las hojas liminares del primero habían sido impresas dos veces, de la manera siguiente: En la ed. de 1815, 1 y 2 estaban en blanco; 3 (= pág. I, por ser la primera hoja impresa) llevaba la portada: "Silva de romances vicjos / publicada por Jacobo Grimm [ambas indicaciones entre dos filetes]. / Vienna de Austria en casa de Jacobo Mayer y Comp. / 1815."; 4 quedaba en blanco. En la supuesta edición de $18 \% 1$, el plegado de la hoja sc había hecho en sentido contrario, lo que daba la paginación siguiente: 
Pero no es ésta, con ser la más difundida y a todas luces la mejor, la única versión del romance que conoce el siglo xvi. Había otra, que andaba en pliegos sueltos; el Cancionero de romances, que por

\begin{tabular}{lll|ll}
1815 & 3 & 4 & 1 & 2 \\
1831 & 1 & 2 & 3 & 4
\end{tabular}

La pág. 3 de $181_{5}$ estaba encolada al dorso de la cubierta (lo que no impedía leerlas por transparencia); su vuelto seguía en blanco; 3 , antes en blanco, llevaba la nueva portada, idéntica a la anterior, salvo en las últimas líncas: "Vienna de Austria, en casa de Schmidl / 1831"; 4 (antes 2) seguía en blanco. La cubierta, por su parté, había sufrido idéntica transformación, sólo que al plegado en sentido contrario se sumaba la impresión invertida:

\begin{tabular}{lll|ll}
1815 & 1 & 2 & 3 & 4 \\
1831 & 7 & 1 & 5 & 8
\end{tabular}

3 y 4 , en cualquier posición, estaban en blanco, y la primitiva cubierta de 1815 iba encolada contra la portada de ese año. La identidad de los tipos indica que la nueva impresión se había efectuado en la misma imprenta, y que un cambio de dueño y no la rareza del libro, como afirman las bibliografías alemanas, había motivado la operación, que mantenía además las caracteristicas externas del volumen. (tipografía e identidad del papel de este cuadernillo con el resto de la obra).

En el ejemplar de la B. N.P. el primer cuadernillo falta redondamente, y a la portada (impresa en un papel verjurado, distinto del papel del libro) sigue la dedicatoria (sin foliar, vuelto en blanco), y a ésta la advertencia $A l$ lector (también sin foliar, numerada al verso: VI, lo que certifica la falta de portada). También la fe de "enmiendas" del ejemplar de París coincide con el ejemplar de 1815 , que la señora Margit Frenk Alatorre ha tenido la amabilidad de revisar para mí: sigue a la pág. 318, y lleva 24 líneas (pág. 5, lín. 7, a pág. 115); al verso lleva 19 líneas más (pág. 119 a 279). Esta cantidad de erratas no corregidas certifica que la ed. de $183_{1}$ no es tal edición, sino una mera reimpresión de cubiertas - o portadas y cubiertas- de ejemplares de la edición princeps.

DepPING-Galiano: la antología de Depping apareció en [Altenburg und] Leipzig, impresa por F. A. Brockhaus, en 1817; la 2 a ed., "considerablemente enmendada por un español refugiado" (Salvá padre), en dos vols., es de Londres, 1825; y la "nueva ed., con las notas de D. Antonio Alcalá Galiano", en dos (o tres) vols. (el tercero, la Rosa de romances de Wolf, aparecida como suplemento de esta antología, tiene dos portadas, y es de 1846), fué también impresa por Brockhaus en "Leipsique", en 1844 . En esta última edición, el romance lleva el núm. 68, pág. 180 .

Durán, Romancero de romances caballerescos e históricos anteriores al siglo xviii, Madrid, E. Aguado, 1832, 2 vols.; I, pág. 2.-El mismo texto, retocado probablemente por él, según su costumbre, aparece en su Romancero general, vol. I, $B A A E E, \mathrm{X}$, núm. 284.

Wolf y Hofmann (Primayera y flor, vol. II, págs. 82-83, núm. 154) siguen la versión del Cancionero s. a., modernizíndola y puntuándola. Al reeditar la Primatera en su Anlologia, vol. VIII, Menf́ndFz Pridayo varia ligeramente la puntuación.

Todos los editores corrigen la crrata del Cancionero s. a., verso 2o: "y es [por él] subiérase en la silla", menos Durán, que suprime redondamente la par- 
lo común "no hizo más que copiar a los pliegos sueltos", parece haber preferido en este caso una versión proveniente de la tradición oral $^{5}$. Que sepamos, son dos los pliegos sueltos en que figura el romance: 1) Aqui comiencã quatro maneras de / Romances: el vno de magdalenica: y el otro de frãcia par/tio la nina..., gót., 4 hs. en $4^{\circ}$, s.l.n.a. [Burgos, Juan de Junta, ca 1547 ]; fué reproducido en facsímil por V. Castañeda y A. Huarte, Colección de pliegos sueltos, agora de nuevo sacados, [Madrid, 1929], págs. 33-40. 2) Comiença vn razonamiento por / coplas en que se contrahaze la germania ... fechas por / Rodrigo de reynosa, gót., 4 hs. en $4^{\circ}$, s.l.n.a. De este último pliego, que está en la B.N.M. [R-9449], el romance pasó -con muchas erratas-al Romancero general de Durán (núm. 285) y de aquí a la Primavera (núm. 154a); también lo copió -con mayor fidelidad-Gallardo, en su Ensayo, IV, cols. 1408-1409, de donde lo tomó CEJADOR, La verdadera poesía castellana, vol. II, Madrid, 1921, núm. 1286.

He aquí el texto del primer pliego suelto, con las variantes del segundo (siguiendo el mismo criterio que antes):

De Francia partió la niña, de Francia la bien guarnida; perdido lleua el camino, perdida lleua la guía;

5 arrimárase a vn roble por atender compañía. Vió venir vn cauallero, dispuesto a marauilla; comiénçale de hablar, tales palabras dezía:

-¿Qué hazéys aquí, mi alma, qué hazéys aquí, mi vida? Allí habló la donzella, bien oyréys lo que dezía:

15 -Espero compañía, señor, que a París lleuo mi guía.
Respondióle el cauallero, tales palabras dezía:

-Si ti pluguiesse, señora, 20 comigo te lleuaría, si querías por muger, o si quieres por amiga. La niña, que staua sola, estas palabras dezía:

25 -Plázeme, dixo, señor, plázeme, dixo, mi vida, si vos me dades la mano, yo luego caualgaría. El cauallero le da la mano,

3o la niña presto subía; andando por su camino, de amores la requería.

tícula. Grimm, Depping-Galiano y Durán traen el verso 36: "de qué os reís, vida mía", en vez de "mi vida", variante que parecería proceder del Cancionero de $155^{\circ}$ o de la Silva del mismo año, que no he podido consultar. Los tres editores escriben en el verso 6 "errada lleva la vía" por "la guía”, variante que, además de enriquecer la rima (guía reaparece cuatro versos más abajo), da una expresión española (llevar o traer la via), usual en textos viejos (cf. “hacia acá trae la vía", en El amor divino, verso 217; RouAnet, Colección de autos, vol. I, pág. 123).

"Cif. Menf́ndiz Pinal, ed. cit. del Cancionero de romances sin año, págs. Ix, xlvin. “¿Oral?”, se pregunta Menéndez Pidal a propósito de este romance (pág. XLıI); "no se parece a la versión que andaba en pliegos sueltos... ni a la que se conserva en un ms. del siglo xv-xvi". 
Aý habló la donzella, bien oyréys, lo que dezía:

35 - Estad quedo, el cauallero, no hagáys tal villanía, que hija soy de vn malato, que tiene la malatía, que el hombre que a mí llegasse

40 luego se le pegaría, que si vos a mí llegáredes la vida vos costaría. Mucho vos ruego, señor que me catéys cortesía.

45 Y a la salida de vn monte y assomada de vna hermita el cauallero yua seguro, la niña se sonrreýa. Aý habló el cauallero,

5o bien oỷréys lo que dezía: - ¿De qué vos reýs, mi alma, de qué os reýs, mi vida? La niña, que estaua en saluo, aquesto le respondía:

55 -Ríome del cauallero y de su gran couardía,

que tiene la niña en el monte y vsaua de cortesía. Desquesto oyó el cauallero, él ahorcarse quería.

Con gran enojo que tiene, estas palabras dezía: -Cauallero que tal pierde grande pena merecía,

65 ćl mesmo se es el alcalde, él mesmo se es justicia, que le corten pies y manos y le cuelguen de vna enzina. $Y$ él en esto estando,

70 ya que hazarlo quería, si no fuera por vna hada, que [a] hablarle venía. Las palabras que le dize quien quiera se las sabía:

75 - No desesperes, cauallero, no desesperes de tu vida, Dios te dará grande victoria en arte de cauallería, que con los viuos le sirue

(Se omite la "Desecha del cauallero con enojo" que sigue al texto). Esta versión introduce en el romance de La hija del rey de Francia rasgos del de La infantina encantada, que comienza "A cazar va el caballero", impreso en el Cancionero de romances sin año y, después (con dieciséis versos más), en el de $155^{\circ}$ (Primavera, núm. $15^{1)}$.

El romance conoce, pues, en el siglo xv y el xvI, tres textos diferentes. El primero, asociado al nombre de un poeta conocido, corresponde a un estado pre-definitivo, dentro de la relatividad que cobra la palabra definitivo referida a un documento tradicional. Ciertas características no han hallado en él la expresión más ajustada que encontramos en la segunda versión, la más difundida por vía lite-

${ }^{-}$Principales variantes del pliego Comiença vn razonamiento por / coplas.... (según el ejemplar de la B. N. M.) : 1 salió; 4 la lleua; 5 arrimada se a; 7 vido; 9 fablar; 13 fabló; 16 para Francia la bien guarnida; 17 respóndele; 19 te: 21 quieres; 27 diéssesme tú la mano; 28 z luego; 30 la niña caualgado auia; 34 oyrés; 35 esta; $3^{6}$ fagriys; 37 fija soy; 39 que quien a mi llegare; 4 llegades; $4^{6}$ de vna montiña; 49 fable [sic]; 52 vos; 57 tenia; 59 el cauallero desquesto oyó; 6o ahorcarse queria; 61 con el gran; 63 el cauallero; 64 qué pena; 65 él se era el alcalde; 66 él se era la justicia; 68 lo cuelguen; 69 y él cstando en esto; 7o y que; 71 fada; 72 a fablarle; 73 que dize; 77 darte ha Dios gran vitoria; 79 se sirue Dios. 
raria -circunstancia en sí misma de valor muy relativo para nuestro estudio-, pero producida, incontestablemente, por tradición oral. La tercera, nuevamente acoplada a un nombre de literato, el de Rodrigo de Reynosa, arrastra detalles y circunstancias de un romance vecino: el ofrecimiento de ser "esposa o amiga" 7 , la autopunición del caballero, el clima de maravilla que envuelve a los personajes. Que esta contaminación no es de la absoluta invención de Reynosa lo muestra el estudio de la tradición popular ${ }^{8}$. Pero lo que interesa examinar ahora es el proceso por el cual la primera versión se incorpora al caudal general del Romancero español: en una palabra, la "romancerización" del romance.

Menéndez Pidal ${ }^{9}$ observa, justísimamente, que es característica

${ }^{7}$ La alternativa no es exclusiva de este romance. Véanse algunos ejemplos del Romancero viejo y de la tradición oral: "Por tus amores, Valdovinos, / yo me tornaré cristiana, / si quieres por mujer, / si no, sea por amiga" (Primavera, núm. 169); "De tres hermanas que tengo / darte he yo la más garrida, / si la quieres por mujer, / si la quieres por amiga. / -Ni la quiero por mujer, / ni la quiero por amiga" (ibid., núm. 140); “¿Tú me llevas por esposa, / o me llevas por amiga?" (versión asturiana del romance de Duardos y Flérida, publicada por Menéndez PIdal en la Revista da Universidade de Coimbra, XI, 1933, pág. 496); "Por Dios me digas, Lunardo, / por Dios y Santa María, / o me llevas por mujer, / o me llevas por amiga" (El cautivo, en Giner Arrivau, Contribución al folklore de Asturias. Folklore de Proaza, Madrid, 1886, pág. 150; MEnéndez Pelayo, Antología, X, pág. 150; María Goyri de Menéndez Pidal, $R A B M, \mathrm{X}, 1906$, págs. $374-386$, y XI, 1907 , págs. 24-36, dice que este romance es conocido en Asturias, Tánger y Portugal: puedc verse una versión portuguesa en P. Firmino A. Martins, Folklore do Concelho de Vinhais, vol. I, Coimbra, 1928, págs. 234); "Se a levas por amiga, / inda t'a imos tirar, / se a levas por mulher, / Deus t'a deixe lograr", gritan los hermanos de la heroína a su raptor en el romance de Albaninha, versión portuguesa del Conde Claros (MarTINs, op. cit., vol. I, pág. 196).

${ }^{8}$ Ya Durán señalaba la poca o ninguna fuerza documental de las asignaciones de los pliegos: "Este romance, que con otras composiciones se halla impreso en el pliego suelto a nombre de Rodrigo de Reinosa, es probable que sea anónimo, porque es común que los editores de esta clase de hojas volantes se den por autores, siendo, cuando más, reformadores de más antiguos romances..." También Wolf y Hofmann, en su nota final al romance, dan a Reynosa el mismo papel: "Reinosa, caso que sea el autor de esta trova, ha tomado por base el asunto del romance antecedente, amalgamándolo con el del romance que dice "A cazar va el caballero" y poniéndole un final de su cosecha". Análogamente, MENÉndez Pidal señala que componer solía significar 'corregir' o 'difundir', y lo mismo nuevamente trobado o nuevamente enmendado (El Romancero, teorias e investigaciones, Madrid, [1928], pág. 65, nota 1).-En cuanto al valor probatorio de las versiones tradicionales, ya lo señaló MENÉndez PeLAYO: "Pero esta contaminación de los dos romances no fué capricho de aquel ingenioso versificador, puesto que tambićn se la encuentra en casi todas las versiones populares" (Antología, vol. X, pág. 91; vol. XII, pág. 519). - Sobre Rodrigo de Reynosa, véase el trabajo bibliográfico de JoHN M. Hill en $H R$, XIV, 1946, págs. 1-21, y el de J. M. DE Cossío en BBMP, XXI, 1945, págs. 9-7o.

${ }^{\circ}$ Flor nueva de romances viejos, Buenos Aires, 1938, pág. 21. 
del Romancero español el conferir unidad de tono -que empieza por lo métrico y continúa por una comunidad creciente de fórmulas y giros- a las materias de diversísima procedencia que componen su caudal lírico-narrativo. Este trabajo se advierte no sólo en lo que pule y elimina, sino también en lo que mantiene. En el caso de nuestro romance, el paralelismo de los versos errado habia el camino, / errado habia la via va proliferando en otras fórmulas semejantes: pláceme, dijo, señora, / pláceme, dijo, mi vida; ¿de qué vos reis, señora, / de qué vos reis, mi vida?

La labor de la tradición oral puede apreciarse también en el desarrollo de los versos alli fabló la doncella, / bien oyrés lo que diría. Menéndez Pidal señala entre los rasgos esenciales del estilo juglaresco el "apóstrofe al público"10. No se trata en nuestro caso de un reclamo directo, puramente vocativo, sino de una intervención indirecta casi, tan delicada, corta y leve que apenas se la advierte como ajena al relato. Más que de un suspenso interesado, tiene función de marco, de telón de boca; está como para recordarnos la presencia de un narrador y de un espectáculo ("no olvidéis que esto es fábula, no os dejéis ganar por el encanto"), como un alarde del cuentista que se sabe escuchado, unido a la advertencia amistosa: "ahora viene lo bueno; estamos en un punto en el que tenéis que atender; ojo a la respuesta". De un solo hiato - en el lugar más señalado, antes del descubrimiento final de la burla- en la versión de Juan Rodríguez, la de los Cançioneros y la de los pliegos sueltos pasan a varias semicadencias (desque lo vido ... le dezia; desque lo oyera, díxole; como discreta, dixo ...; aquesto le respondia), y a la aparición, ya sin peso, de fórmulas expresas, comunísimas en el Romancero, como estas (o tales) palabras decia, comiénzale de hablar..., ahi habló... bien oiréis lo que decia $^{11}$.

Así también, la fórmula de cortesía Pláceme, dixo, señora... reaparece, por ejemplo, en el romance III de Montesinos (Primavera, núm. 117) y en el de Galiarda (Primavera, Apéndice I, núm. 47) ${ }^{12}$, y lo mismo ocurre con otras expresiones: "que si no me la pagares, / muy caro te costaria" dice el romance Por el val de las Estacas en el Cancioneiro musical e poético da Biblioteca Públia Hortênsia (ed. M. Joaquim, Coimbra, 1940, pág. 154, versos 35-36); el verso final en los pliegos sueltos es igual a otro eneasílabo de un Romance

${ }^{10}$ En la lírica gallega y provenzal: Poesia juglaresca y juglares, pág. 206; en el Poema del Cid: ibid., págs. 330 y sigs.; en Berceo: ibid., págs. $35^{1}$ y sigs. Por lo que toca a Berceo, lo sigue Díaz Plaja, La poesía lírica española, Barcelona, 1937, págs. 36-37.

${ }^{11}$ Sobre estas y otras fórmulas de "introducción al diálogo", véase RUTI House Webber, Formulistic diction in the Spanish ballad, Berkeley and Los Angeles, 1951, págs. $183^{-1} 89$.

1.2 Ibid., págs. 194-195. 
de Alfonso el Sabio (Primavera, núm. 62): "ayúdeme Jesucristo / y su madre Santa Maria".

Consideremos también otro rasgo estilístico del Romancero: la "fórmula gramatical, muy común en los viejos romances, que consiste en duplicar el verbo o la palabra que haga sus veces, ante el vocativo de la oración", y que en los romances de la tradición oral es, según Carolina Poncet ${ }^{13}$, "signo de la procedencia antigua" de un texto. La autora da varios ejemplos, entre ellos, el "Tregua, tregua, adelantado" de Álora la bien cercada; "Diga, diga, la señora" (La ausencia); "Bebe, bebe, mi caballo" (Conde Olinos). Nuestro romance trae vuelta, vuelta, mi señora, y tate, tate, el escudero (caballero). La primera frase aparece en algunos romances fronterizos: "Vuelta, vuelta, caballeros, / vuelta, vuelta a la batalla!" (Primavera, núm. 95); "Buelta, buelta, Pero Hernández, / que no es buena señal ésta" (romance Caballeros de Moclin, según "un ignorado pliego suelto gótico del siglo Xvi”, en MENÉndez Pidal, El Romancero español, pág. 40), y en varios caballerescos: " Vuelta, vuelta, caballeros, / que por aquí no hay pasaje!" (Primavera, núm. 164, vs. 695-696); “'Vuelta, vuelta, los franceses, / con corazón a la lid!" (Primavera, núm. 183). La fórmula anda ahora en el Hilo de oro infantil por todo el ámbito del español; y sobre todo la conocemos hoy asociada a una treta semejante a la del caballero: "Vuelve, vuelve, caballero, / vuélvete por tu montera", "vuelva usted, el caballero, / se le olvida la montera" (La serrana de la Vera, versiones publicadas por N. Alonso Cortés en $R H i, \mathrm{~L}, 1920$, págs. 226 y 227).

En algunas versiones tradicionales de La hija del rey de Francia encontramos desarrollado este episodio del falso retorno: el caballero finge haber olvidado una espuela o la espada. La niña, manifestando su verdadera condición, finge creerlo, y le responde que no importa: si el objeto perdido era de plata, sus padres se lo darán de oro; pero a veces responde con mayor viveza: "Mientes, mientes, caballero, / que en el flanco la traías"14.

La fórmula tate, tate, servía en los romances épicos para apaciguar el ardor combativo: "TTate, tate, caballeros! ¡Tate, tate, hijosdalgo!"

13 [María] Carolina Poncet y de Cárdenas, "El romance en Cuba", Revista de la Facultad de Letras y Ciencias, XVIII, 1914, págs. $180-261$ y 278-322. Cito por la separata, La Habana, 1914, pág. 67. - Sobre este rasgo estilístico, véase la citada obra de R. H. Webrer, págs. 215-216.

${ }^{14}$ Esta frase es también frecuente en el Romancero tradicional, siempre referida a una situación parecida y a un arma. La conversación entre la infanta y Gerineldo, luego de la visita del rey, que deja su espada entre ambos, es muy parecida en ciertas versiones al episodio en el romance de La hija del rey de Francia: "Gerineldo, Gerineldo, / despierta si estás dormido, / que la espada de mi padre / entre los dos ha dormido. / -Miente, miente, la Infantina, / que la traje yo conmigo. / -Miente, miente, Gerineldo, / que yo bien la he conocido" (Cossío y Maza Solano, Romancero popular de la Montaña, vol. I, Santander, 
(Primavera, núm. 16); “Tate, tate, que es el rey / éste que llegado había" (ibid., 67). En los romances novelescos se convierte en un rechazo de requerimientos amorosos: "Tate, tate, dijo, fraile / que a mí no llegarás" (ibid., 191); "Tate, tate, caballero, / casada soy ..." (La malcasada del pastor $\left.{ }^{15}\right)$; "Tate, tate, caballeros, / non fagades bellaquía; / tate, tate, caballeros, / que mi honra en vos se fía" (La hija de la viudina, en J. Menéndez Pidal, Poesia popular, op. cit., pág. 173, núm. 42).

Ofrece gran interés considerar la localización creciente -localización y creciente en un sentido estrictamente literario- de la fábula de este romance: de unos vagos Montes Claros - los hay en la cordillera divisoria de las dos Castillas, y su paisaje de montiñas y aguas va bien con la aventura de las infantinas; pero más que a geografía real, ¡cómo sabe el de estos montes a nombre de ciclo carolingio !16 se pasa a la plenitud de Francia y su villa. Plenitud no meramente, chatamente geográfica: sí plenitud de evocación, de nombres a todos conocidos, y con lejanía no de imposible, sino casi a la mano. "Los poetas conocían a Francia como una tierra con una ciudad (París) y un emperador (Carlomagno)"'17, y esta precisión les bastaba. Francia era para los romanceristas, "Francia la noblescida" (Durán, Romancero, núm. 367), "Francia la bien guarnida", como en nuestro romance o en el de Rosaflorida (Primavera, núm. 179), o, más aún -y el epíteto sólo cede apenas ante France la doulce-, "Francia la natural" (Primavera, núms. 164, 178, 186, 190, 191, 193, 194).

Y en Francia, París, la única, atraerá a los poetas del Romancero con ese fervor que pondrá Borges para cantar a Buenos Aires. Entre

[1939], pág. 129, núm. 67; no menciona esta variante Menéndez Pidal, "Sobre geografía folklórica", $R F E$, VII, 1920, págs. 229-398). En la Venganza de honor, el caballero que se alza con la niña "trata de quitarle el honra, / y la dice con falsía: / -Más abajo do bebimos / quedóse la espada mía. / -Mientes, mientes, caballero, / qu'ende la traes tendida" (Juan Menéndez Pidal, Poesia popular. Colección de los viejos romances..., Madrid, 1885, pág. 166, núm. 38; Menéndez Pelayo, Antología, vol. X, pág. 10o). "Miente, miente, la viudina", le dicen los caballeros que tratan de robar a su hija, cuando ella la esconde (ibid., pág. 172, núm. $4^{2}$ ).

1: En Menéndez Pidal, "Catálogo del Romancero judío-español”, núm. 72, ${ }_{2}$ a versión, en Los romances de América y otros estudios, Buenos Aires, 1941, pág. 74; Robolfo Gil, Romancero judeo-español, Madrid, 1911, pág. xxir, núm. 3. La versión de Bf́sichou (RFH, VI, 1944, pág. 67), dice "Tate, tate, tú, el paje".

16 Además de figurar en el romance de Calaínos (Primavera, núm. 193), los Montes Claros, que ya aparecen en el Mio Cid, designan una región de África y son, sobre todo, un "nombre común", que llega a los cronistas de Indias; cf. Menéndez Pidal, Cantar de Mio Cid, Madrid, 1944-1946, vol. II, págs. $7^{6.4}-76_{5}$.

${ }_{17}$ William J. Entwistle, European balladry, Oxford, 1939, pág. 175. 
las ciudades provistas de un adjetivo determinado ${ }^{18}$, la de más hermosa resonancia será París: no tanto "París la grande" (Primavera, 173), sino París, la villa por antonomasia, con el viejo artículo épico: "París esa ciudad" (casi en todos los romances carolingios: Primavera, núms. $172,187,188,192,193,195$, etc.). Rastros de esa geografía exclusiva ${ }^{19}$ perviven en la tradición americana ${ }^{20}$.

Tal es la suerte de Francia. Semejante es la de su familia real. La hija del rey de Francia es la heroína de una novela en verso, imitada, más que restaurada -él mismo lo confiesa-, por DuRán (Romancero, núms. 308 y sigs.). Entre otros ejemplos, María Rosa Lida ${ }^{21}$ cita éstos del Conde Arnaldos (versión completa) y de Tiempo es, el caballero.... "Hijo soy del rey de Francia, / nieto del de Portugal"; "Hijo soy del rey de Francia, / mi madre es doña Beatriz"; y la hija del rey de Francia sirve para barridos y fregados - en materia novelesca, se entiende- en el romancero catalán; basta un solo ejemplo: es la hija del rey francés la vengada de su honor que pide a su raptor la espada para ensanchar su saya estrecha, y lo mata con ella ${ }^{22}$. A propósito de La dama de Aragón, que en algunas versiones se jacta de su parentesco con la casa de Francia - y no faltó quien buscara la coyuntura genealógica de esta afirmación- dice con su acostumbrada exactitud William J. ENTWistle:

La extrañeza del elemento novelesco fué notada hasta por quienes compusieron las versiones castellanas; a menudo tienen cuidado de colocar la escena fuera de Castilla, de emplear nom-

18. Véase el trabajo de L. SPITzer, "El sintagma Valencia la bella", RFH, VII, 1945, págs. 259-276, especialmente pág. 261.

19 Recuérdese: "Cata Francia, Montesinos, / cata París la ciudad, / cata las aguas de Duero / do van a dar en la mar" (Primavera, núm. 176); "En Francia habemos estado, / en Mantua esa ciudad" (ibid., 166, vs. 39-40); "Hoy entre los doce pares / veo gran ruido armado, / y el imperio de París / todo escandalizado" (ibid., 177a, vs. 279-282).

20 "Y para evitar cuestiones / me fuí a la ciudad de Francia" (J. Vicuña Cifuentes, Romances populares y vulgares recogidos de la tradición oral chilena, Santiago de Chile, 1912, pág. 341); "Mató un alcald'en su tierra, / y por una güena causa, / y par evitar custodia / se ju'a la viya de Fransia" (AURElro M. Espinosa, "Romancero nuevo mejicano", RHi, XXXIII, 1915, págs. 494 y 495); "Él es un rico barón / de la suidá de Guayanas . . / . . ya el enemigo / pegó'n la viya de Fransia” (ibid., pág. 495; DuRÁn, Romancero, núm. 1342). - En las canciones líricas españolas no faltan geografías similares. Un cantar de Schindler (Folk music and poetry of Spain and Portugal, New York, 1941, pág. 361) une el vicjo tema - que va de la bucólica griega al rococó- de la fidelidad equiparada a la constancia de una corriente de agua y su imposible cambio o regresión, con la precisión geográfica que apuntamos: "No te he de olvidar / aunque el río de Francia / diera la vuelta al mar."

21 "El romance de la misa de amor", $R F H$, III, 1941, pág. 31, nota 1.

${ }^{22}$ Milá y Fontanals, Romancerillo catalán, en Obras completas, vol. VIII, pág. 405, núm. $55^{1}$. 
bres carolingios o análogos a ellos (por ejemplo, Conde Dirlos), de aludir a Francia o por lo menos a Aragón, que ya no es Castilla y que además está camino a Francia. Así, las palabras "Rico Franco aragonés", en el romance de Rico Franco, son por sí solas indicio de que existió una balada francesa más antigua; de hecho, tenemos que remontarnos hasta el Halewijn holandés, pasando por el Frère Renaud... En la versión catalana [de la Misa de Amor] encontramos, sin embargo, un texto más auténtico y revelador: N'es filla del Rey de França, germana del d'Aragó. No tenemos aquí "el vivo recuerdo de la monarquía catalano-aragonesa y de su unión con la casa de Francia"; en mi opinión, tales palabras quieren decir, como en otros casos: "este romance no es castellano; hay que buscar en Francia su fuente inmediata" 23 .

Ese tema extranjero aparece, pues, y casi desde el comienzo, enteramente "romancerizado". Fórmulas y expresiones lo unen a los romances de asunto histórico nacional y a los de materia novelesca de toda procedencia: que expresiones semejantes corresponden siempre, en el Romancero, a situaciones semejantes -o, por lo menos, de contenido similar - será objeto de un estudio ulterior. Baste señalar ahora la incorporación al romance de esas fórmulas que dan total identidad de estilo al Romancero; y para que la adopción sea más completa, hasta la misma indicación de que se trata de un relato extranjero con personajes extranjeros y localizado fuera de España, con lo que eso significa como indicación de procedencia, mancomuna este romance con otros que no son de los más ajenos al espíritu español, ni, por lo tanto, de los menos difundidos. Paradójicamente, La hija del rey de Francia se españoliza precisando su condición de extraña; y, paradójicamente también, esta precisión es una muestra más de la fuerza con que penetra su tema en la tradición popular española.

Daniel Devoto

Buenos Aires - París.

${ }^{23}$ W. J. Entwistle, "La dama de Aragón”, HR, VI, 1938, pág. 191. Cf. también su European balladry, pág. 174: "El hecho es que casi todos los romances de aventuras corrientes en Castilla eran de origen extranjero... Una señal de importancia es que frecuentemente la acción de tales romances se sitúa en Francia (aunque Aragón deba mencionarse como pais intermedio entre Francia y Castilla, a través del cual pasaban las baladas que entraban por ahí a Castilla)". Aragón tuvo, además, crecida población francesa: Barbastro, sede episcopal, fué enteramente repoblada con franceses. Aunque circunscrito a una época muy temprana, puede consultarse para esto el libro de M. Defournfaux sobre los franceses en España (Paris, 1949). 